\title{
ITC Tokyo 2015 Special Issue, \\ -Papers from International Tribology Conference, Tokyo 2015 (Part 1)-
}

The 7th International Tribology Conference, Tokyo 2015, was held on 16-20 September 2015 at Katsushika Campus of Tokyo University of Science, located at the east end of Tokyo Metropolitan, Japan.

At the ITC Tokyo 2015, over 600 registered participants from 30 countries and about 50 industrial exhibitors attended the conference. During the conference, about 400 oral talks and 200 posters were presented. Excellent papers submitted to the Tribology Online have subsequently undergone the normal peer-review process by multiple reviewers. Many of accepted papers were published in this Special issue, Part 1, and other papers will appear in the next Special issue, Part 2.

On behalf of the ITC Tokyo 2015 Conference Committee, and the Editorial Committee of Tribology Online, I, the Chair of the ITC Tokyo 2015, and the Guest Editor of Tribology Online, acknowledge the authors' efforts to submit their papers to these Special issues. I also express my sincere thanks to the Editors, the Reviewers, and the Publication Coordinators for their efforts to complete the peer-review processes and the publication work.

\section{Shigeka Yoshimoto}

Chair of the ITC Tokyo 2015

Guest Editor
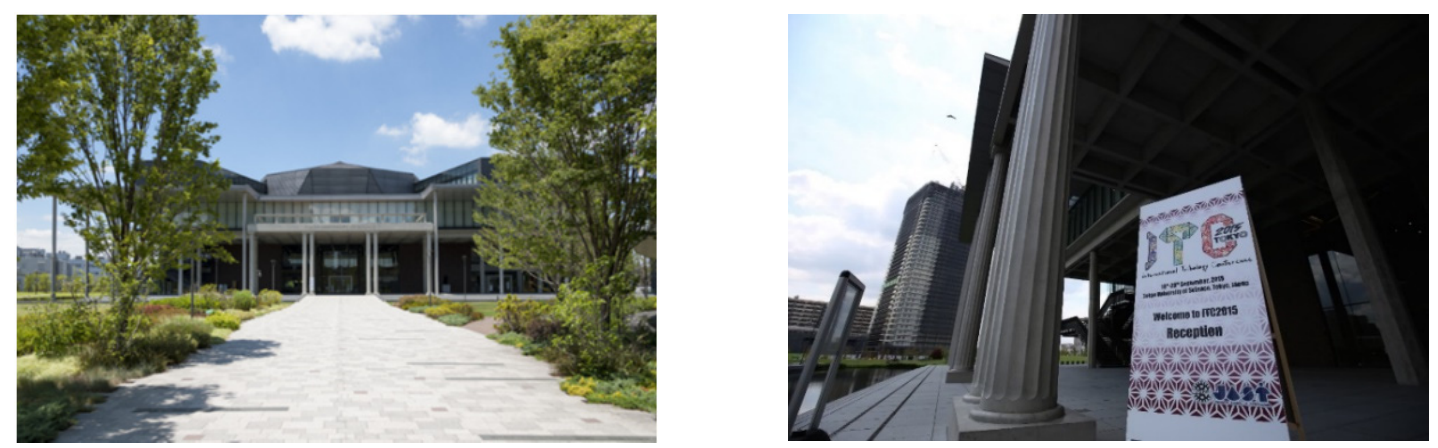

Conference Venue: Tokyo University of Science

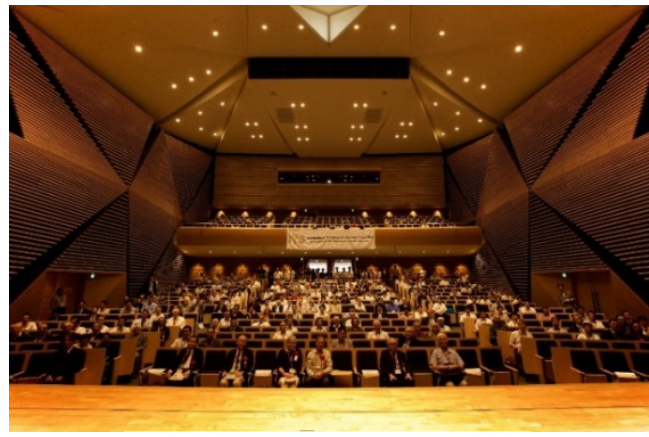

Opening Ceremony

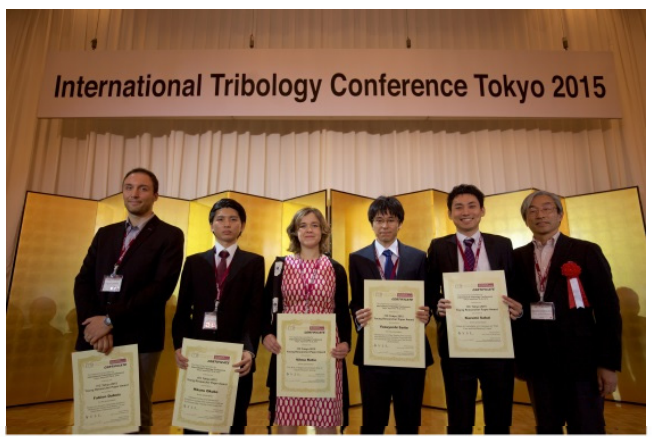

Winners of ITC Young Researcher Paper Award left to right: Fabien Dubois (Universite de Lyon), Hikaru Okubo (Tokyo University of Science), Vilma Ratia (Tampere University of Technology), Yasuyoshi Saito (Tohoku University), Kazumi Sakai (JX Nippon Oil \& Energy Corporation), Masabumi Masuko (TROL Editor-in-chief) 